This is the peer reviewed version of the following article:

Gabriele Valentini, Gianluca Allegro, Chiara Pastore, Emilia Colucci, Ilaria Filippetti

Post-veraison trimming slow down sugar accumulation without modifying phenolic ripening in Sangiovese vines

JOURNAL OF THE SCIENCE OF FOOD AND AGRICULTURE Volume 99, Issue 3, FEBRUARY 2019, Pages 1358-1365 which has been published in final form at https://doi.org/10.1002/jsfa.9311

This article may be used for non-commercial purposes in accordance with Wiley Terms and Conditions for Use of Self-Archived Versions. 


\section{Post-veraison trimming slow down sugar accumulation without modifying phenolic ripening in Sangiovese vines}

\section{RUNNING TITLE: Post-veraison trimming of Sangiovese vines}

Gabriele Valentini, Gianluca Allegro, Chiara Pastore, Emilia Colucci, Ilaria Filippetti*

Dipartimento di Scienze Agrarie, Università di Bologna, viale Fanin 44, 40127, Bologna, Italy.

*Corresponding author: ilaria.filippetti@unibo.it; fax +390512096400

This article has been accepted for publication and undergone full peer review but has not been through the copyediting, typesetting, pagination and proofreading process which may lead to differences between this version and the Version of Record. Please cite this article as doi: $10.1002 /$ jsfa. 9311 


\begin{abstract}
BACKGROUND: Vineyard strategies have recently been developed to fight the effects of global warming on grapevine, which is causing fast grape ripening, excessive sugar accumulation in berries and high alcohol levels in wines. Among these, we evaluate the effectiveness of post-veraison trimming to slow down sugar accumulation without modifying phenolic ripening, in Sangiovese vines grown in highly fertile and wellwatered soil.
\end{abstract}

RESULTS: The removal of about two thirds of leaf area by shoot trimming after veraison led to sugar content reduction without effect on yield. Total and extractable anthocyanins, skin and seed tannins showed no significant variation at harvest after the treatment during the three years trial, while the replenishment of carbohydrates in canes at the end of the trial was negatively affected.

CONCLUSIONS: These results indicate that in highly fertile and well-watered soil, post-veraison trimming may represent a powerful tool for decreasing sugar concentration at harvest without affecting yield and total and extractable phenolic compounds but, the starch reserves reduction compared to the control serves as a warning about repeated trimming over the years. 
KEYWORDS: anthocyanin, phenolic maturity, source limitation, tannin, technological maturity

\section{INTRODUCTION}

In recent years we have been witnessing a variation in climatic conditions affecting mainly a rise in air temperature, a steady carbon dioxide concentration increase in the atmosphere and changes in rainfall distribution throughout the agricultural area and season. ${ }^{1,2,3,4}$ Model output for global wine producing regions predicts an average warming of $2{ }^{\circ} \mathrm{C}$ in mean temperature over the next 50 years and a $\mathrm{CO}_{2}$ concentration range between 541 and 970 ppm.,

The climate profoundly influences the production of quality grapes and identifies suitable areas for grapevine growing. In fact, one of the tools that scientists have long used to map areas suitable for the cultivation of specific grape varieties is the definition of bioclimatic indices mainly based on temperature. ${ }^{7,8}$

Nowadays global warming is affecting grapevine development and phenology, which results in earlier harvest dates, ${ }^{9}$ fast grape ripening, excessive sugar accumulation in berries and a resulting high alcohol wine. ${ }^{10,11,3,12,13,14,15}$ Keller, ${ }^{16}$ highlights that in many 
cases these phenomena have also been coupled to faster depletion of organic acids, high $\mathrm{pH}$ and atypical green flavors in the grape because of the shortening ripening period and shift towards the hotter part of the season.

Focusing on phenolic compounds in black berry varieties it has been clearly verified that the high temperature negatively impacts color intensity ${ }^{17,18,19,20}$ giving rise to poor colored wine. Recent studies focused on the molecular mechanism of lower anthocyanin concentrations under high temperature confirmed the anthocyanin synthesis inhibition and promotion of their degradation. ${ }^{21,22}$ These results supported the occurrence of thermal decoupling of anthocyanin and sugar accumulation already observed in Cabernet Franc and Shiraz varieties exposed to a high temperature regime $-2.3-3.2{ }^{\circ} \mathrm{C}$ higher than the control ranging from $30^{\circ}$ to $40^{\circ} \mathrm{C}$ - during the vegetative season. ${ }^{23}$ The earlier harvest date caused by these conditions often matched unacceptable phenolic conditions and wines resulting as unbalanced with excessive levels of alcohol, poor color and high astringency.

High temperatures seem to have less influence on the synthesis of tannins during ripening ${ }^{24,25,26}$ compared to anthocyanins, since tannins are the most stable phenolics under diverse growing conditions. These compounds accumulate in the berry skin and seeds from fruit-set to veraison, ${ }^{27}$ having a rapid increase to a peak followed by a gradual decline after veraison with less or null variation during maturation close to harvest. $^{28,29}$

Following frequent cases of unbalanced red wines marked by high astringency during the last years, interest in the extractability of flavonoids during ripening is growing. On 
Sangiovese berries, a different trend of the main phenolic compounds was noted during ripening, with anthocyanins and skin tannins extractability increasing while seed tannins extractability maintained a stable trend. ${ }^{30}$

Although in the long term this scenario will result in a latitude shift, certainly influencing the distribution of grapes on Earth with new areas becoming viable on the northern fringes and changes in varietal suitability in the existing growing regions, ${ }^{31}$ in the short term some agronomic techniques can mitigate the negative impact of high temperatures on berry quality.

Different vineyard strategies are now available to slow down sugar accumulation and decelerate an overly quick and unbalanced berry ripening ${ }^{32,33,34,35,36}$ and the most effective of these are based on the induction of source limitations during ripening through post-veraison leaf removal of the upper part of the shoots. ${ }^{37,38}$ The physiological background is that, around veraison, leaves located on the apical part of the canopy are the most functional and are still able to elaborate carbohydrate. In particular, Palliotti et al. ${ }^{38}$ stated that mechanical post-veraison leaf removal practiced at 16-17 ${ }^{\circ}$ Brix removing $30-35 \%$ of apical leaves reduced sugar accumulation without affecting total anthocyanins and phenols in grape skin.

Previous study on cv. Sangiovese showed that post-veraison trimming could delay sugar accumulation without affecting the evolution of anthocyanins and seed tannins in grape, ${ }^{29}$ but in our knowledge no research reports the effects of this or similar techniques ${ }^{38}$ on the evolution of the extractable portion of anthocyanins and skin tannins involved on the phenolic ripening advancement. A recent paper on the same variety 
showed that ripening stage had a strong impact on the increase of extractability of anthocyanins and skin tannins independently of the accumulation of their total amount, but not of seed tannins ${ }^{30}$.

Moreover, since it was evident that when Sangiovese vines were grown on low-vigour conditions, the post veraison trimming over years could induce a yield reduction, ${ }^{29}$ the aim of our 3-year study was to evaluate whether post-veraison trimming can be applied to slow down sugar accumulation without alteration of the phenolic ripening in highly fertile soil. In order to obtain practical information about the fate of anthocyanins and tannins during ripening, extractions were performed in a model hydroalcoholic solution.

\section{EXPERIMENTAL}

\section{Plant material and experimental layout}

The trial was conducted over 2012, 2013 and 2014 seasons on an 8-year-old irrigated vineyard of Vitis vinifera L. cv. Sangiovese (12 T clone) grafted onto SO4 rootstock, located on flat land close to Bologna, Italy (latitude $44^{\circ} 25^{\prime} \mathrm{N}$; longitude $11^{\circ} 28^{\prime} \mathrm{W}$ ). The vines were trained to a vertically shoot positioned (VSP) spur pruned cordon and spaced $1 \mathrm{~m}$ intra-row and $2.8 \mathrm{~m}$ inter-row, with 12 buds per vine. During the growing season, the number of shoots and bunches were kept uniform by shoot and bunch thinning. All vines were trimmed in June removing only the apical part of the shoots on each vine according to the usual VSP spur-pruned cordon practices.

The experimental design included 32 vines in four randomized blocks, assigned to the following treatments: untrimmed control (C) and shoot trimming applied after full veraison, leaving 8 basal nodes and related laterals (TRIMM). 
TRIMM vines were trimmed manually when the total soluble solids (TSS) reached 15$16^{\circ}$ Brix: day of the year (DOY) 221, 231 and 225 in 2012, 2013 and 2014 seasons respectively.

Mean daily air temperature and rainfall data were recorded each year from April to September at a weather station located close to the trial site.

\section{Vegetative and yield data}

Each year, after trimming, leaf area was estimated after determining the linear relationship between main and lateral shoots length $(\mathrm{cm})$ and corresponding leaf area $\left(\mathrm{cm}^{2}\right)$ for 20 shoots collected from C and TRIMM vines. Leaf area was measured with a LI-3000A leaf area meter (Li-Cor Biosciences, Lincoln, NE, USA). Regression curves (data not reported) were used to estimate leaf area on each vine by measuring the length of all main and lateral shoots.

At harvest the collected data included, for both treatments: yield, bunch number and weight, berry mass. Rot incidence was expressed as percentage of infected area per bunch.

Pruning weight per tagged vine was measured every winter.

\section{Berry sampling}

Every 10 days, from one week after full veraison to harvest (on October 2 in 2012 and 2013; on September 30 in 2014), a random sample of 80 berries was collected within each block and per treatment (640 berries total) by cutting through the pedicel with scissors. Each sample was then divided into two subsamples that were immediately processed to determine: a) must biochemical parameters (40 berries); b) extractable 
anthocyanins and tannins (40 berries). In each year at harvest two extra berry samples (of 20 berries each), collected within each block and per treatment (320 berries total), were frozen and stored at $-80{ }^{\circ} \mathrm{C}$ for total anthocyanins and total tannins analyses.

\section{Biochemical analysis of musts}

Must parameter subsamples (40 berries each) were analyzed to determine TSS using a temperature-compensating Maselli R50 refractometer (Maselli Misure, Parma, Italy). Must $\mathrm{pH}$ and titratable acidity were measured using a Crison Titrator (Crison Instruments, Barcelona, Spain).

\section{Extraction of anthocyanins and tannins using a model hydroalcoholic solution}

Whole (not ground) skins and seeds from 40 berries were soaked separately and shaken daily, in tubes containing $80 \mathrm{~mL}$ of a hydroalcoholic solution for 15 days at $28{ }^{\circ} \mathrm{C}$. The duration and temperature imposed on the extractions were chosen to simulate winemaking conditions and thus determine the concentration of extractable anthocyanins and tannins. The hydroalcoholic solution comprised $6 \mathrm{~g} / \mathrm{L}$ tartaric acid, 40 $\mathrm{mL} / \mathrm{L} 1 \mathrm{~N} \mathrm{NaOH}, 100 \mathrm{mg} / \mathrm{L}$ potassium metabisulphite and a proportion of ethanol that was raised from 0 to $13 \%$ in the first 12 days of extraction. This concentration was reached by adding $2 \mathrm{~mL}$ of ethanol absolute ( $12 \mathrm{~mL}$ total) every two days to simulate alcoholic fermentation. The extracts were centrifuged (15 minutes, $13000 \mathrm{rpm}$ ) and aliquots of the supernatant $(400 \mu \mathrm{L})$ were dried under vacuum at $20^{\circ} \mathrm{C}$. Pellets were stored at $-20^{\circ} \mathrm{C}$.

\section{Exhaustive extraction of anthocyanins and tannins}


Total anthocyanins were extracted from the skins of 20 berries by soaking the peeled skins in $100 \mathrm{~mL}$ methanol for $24 \mathrm{~h}$, then storing the extracts at $-20{ }^{\circ} \mathrm{C}$. Total tannins were extracted from the skins and seeds of 20 berries ground separately to a fine powder before extracting $1 \mathrm{mg}$ of the sample in $1 \mathrm{~mL} 70 \%(\mathrm{v} / \mathrm{v})$ acetone in water, for 24 hours in dark room.10 Skin and seed extracts were then centrifuged (15 minutes, $13000 \mathrm{rpm}$ ) and two $400 \mu \mathrm{L}$ aliquots of the supernatant were dried under vacuum at $20{ }^{\circ} \mathrm{C}$. Pellets were stored at $-20{ }^{\circ} \mathrm{C}$.

\section{Anthocyanin and tannin determinations}

Total and extractable anthocyanins were separated by HPLC as described by Mattivi et al. ${ }^{40}$ using a Waters 1525 instrument equipped with a diode array detector (DAD) and a reversed-phase column (RP18 $250 \times 4 \mathrm{~mm}, 5 \mu \mathrm{M}$ ) with a pre-column (Phenomenex, Castel Maggiore, BO, Italy). The concentration was determined by measuring absorbance at $520 \mathrm{~nm}$. A calibration curve was established using a malvidin-3-glucoside standard (Sigma-Aldrich, ST. Louis, MO, USA).

Total and extractable tannins were measured by HPLC with the equipment described above. The concentration of tannin in skins and seeds was determined according to the methods previously reported ${ }^{41,42}$ by measuring absorbance at $280 \mathrm{~nm}$. A calibration curve was established with commercial standards of catechin, epicatechin, epicatechin gallate and epigallocatechin (Extrasynthese, Genay, France).

\section{Carbohydrate storage in cane wood}

At the end of March 2015, two weeks before budburst, grapevine tissue from basal part of each cane (node 3) was collected during winter pruning and analyzed as reported by 
Edward et al. ${ }^{43}$ to investigate the replenishing of reserves in terms of soluble sugar and starch concentrations.

\section{Statistical analysis}

All the data collected were analyzed statistically by the mixed procedure available in SAS v9.0 (SAS Institute, Inc., Cary, NC, USA). Incidence values of rot are subjected to arcsin square root transformation before analysis. Treatment comparisons were analyzed using the Tukey test with a cut-off at Pd0.05.

\section{RESULTS}

A careful analysis of the most important climatic parameters during the three years of the trial showed that 2014 was extraordinarily wet and cool, with total rainfall and average of the mean and maximum air temperature (calculated from April through September) reaching the highest and the lowest values respectively during the period of the trial (Table 1).

\section{Vegetative, productive and berry compositional traits}

Starting from uniform vines, trimming reduced leaf area by approximately $67 \%$ compared with those of the control and no lateral regrowth was recorded at harvest in any vintage (Table 2).

The bunch number per meter of cordon was uniformed and bunch mass and berry mass were unaffected by trimming. As regards the health of the grapes, no differences between the two treatments were found for rot infections, despite the highest level registered for both in 2014, compared to the previous year (data not reported). TRIMM had a strong effect in reducing leaf-to-fruit ratio and on the soluble solids concentration 
( ${ }^{\circ}$ Brix) that was significantly lower at harvest than that of $\mathrm{C}$ berries, while final must titratable acidity and $\mathrm{pH}$ content showed no difference among treatments (Table 2).

The levels of both total and extractable anthocyanins and total and extractable tannins from the berry skin and seeds at harvest, were not affected by the trimming (Table 3). As a consequence, the extractability of anthocyanins, skin and seed tannins, calculated as a percentage relative to the total amount at harvest showed no difference between treatments.

\section{Evolution of soluble solids and phenolic compounds during ripening}

On a 3-year basis, TRIMM reduced TSS at harvest by $1.4^{\circ}$ Brix as compared with that of $\mathrm{C}$ (Table 2, Figure 1). In particular, Figure 1 highlights that starting from ten days after trimming until harvest time, the difference in soluble solids accumulated between TRIMM and C vines remains constant for both 2012 and 2014 (Figure 1A, 1C). The situation was different for 2013 where a significant gap occurs only in the last two weeks before harvest (Figure 1B).

The evolution of extractable anthocyanins (Figure 2) did not vary among treatments and increased until harvest - in the first two years - when the trends appeared very similar with a daily increase of about $1 \mathrm{mg}$ of anthocyanins per $\mathrm{kg}$ of grapes (Figure 2A and 2B). In the last year, the concentration of extractable anthocyanins reached maximum values two weeks before harvest and then decreased, especially in the control vines (Figure 2C).

The concentration of both extractable skin (Figure 3) and seed (Figure 4) tannins did not vary among treatments during ripening. In particular, as shown in Figure 3, the level of 
extractable skin tannins increased during ripening in 2012 that was hotter and less rainy (Figure 3A, Figure 3B), while, in 2014, the amount of tannins extracted into solution decreased slightly from post-veraison to harvest (Figure 3C).

For extractable seed tannins, it is evident that the highest concentration was found around the time of trimming. Afterwards, the amount decreased strongly during the first ten days of ripening and then stabilized following a plateau.

\section{Pruning weight and carbohydrate storage in cane wood}

As expected, TRIMM vines presented a strong reduction (56\%) of one-year-old wood for each trial year in comparison to C (Table 4). In March 2015, two weeks before budburst, the sample of basal canes collected to investigate the replenishing of reserves in these parts of the vine showed that TRIMM had accumulated 29\% less starch reserves compared to untreated control at the end of the three years trial, while no differences were found in terms of soluble sugars content.

\section{DISCUSSION}

As reported by several authors, the level and timing of canopy leaf removal, performed via defoliation or trimming, can alter phenology of berry components during grape ripening and yield. ${ }^{44,45}$ In particular, leaf removal induced a reprogramming of sourcesink balance and may mitigate the excess of sugar accumulation due to climate change. $^{46}$

Over three years of study on cv. Sangiovese, the strong reduction of about two thirds of leaf area, corresponding to the distal part of the shoot, imposed after veraison by shoot trimming, led to a decrease of leaf-to-fruit ratio largely below the threshold of $1 \mathrm{~m}^{2} / \mathrm{kg}$, 
with the expected reduction in sugar content, in agreement with Kliewer and Dokoozlian $^{45}$, but without an effect on yield. Since no lateral re-growth was recorded in any vintages the results are mainly due to well-established leaf age versus net photosynthesis $\left(\mathrm{P}_{\mathrm{n}}\right)$ relationships ${ }^{47,48,49}$ and not to the competitive effects of new developing laterals.

In a previous research that tested the post-veraison trimming technique for three consecutive years on a low vigor and non-irrigated vineyard of Sangiovese ${ }^{29}$ a yield constraint of treated vines was found in the last season. The behavior of Sangiovese grown in a severe water stress condition, which tends to sacrifice basal leaves keeping the younger ones much more functional, ${ }^{38}$ may corroborate this response towards yield reduction. This situation did not occur in our case thanks to the irrigation that limited water stress damage, especially during the hottest season (2012), and to the wellbalanced vine conditions at the beginning of the treatments. Furthermore, we can speculate that in present conditions the remaining basal leaves may reveal a photosynthetic compensation mechanism ${ }^{50}$ in order to ensure the production and a sufficient level of reserves for the following year.

Several authors ${ }^{50,38,29,36}$ have previously shown that the limitation of sources immediately after veraison has no influence on the concentration of anthocyanins and tannins in berries and our results at harvest during the three years confirm these findings. A recent work ${ }^{46}$ reported that the strong reduction in leaf-to-fruit ratio (from $1.15 \mathrm{~m}^{2} / \mathrm{kg}$ to $0.33 \mathrm{~m}^{2} / \mathrm{kg}$ caused by the removal of $80 \%$ of leaf area) at veraison resulted in a decrease of soluble solid accumulations associated with a significant 
reduction of secondary metabolites, such as anthocyanins, without substantial differences in their composition. Our results are partially dissimilar to these findings, probably due to the postponing of source limitations - at the end of veraison - and the leaf-to-fruit ratio level, which was set to a higher value, showing a lower reduction of leaf area (about 63\%).

Our results, over three years of study, registered no difference between treatments on the concentration of extractable anthocyanins and tannins in wine-like solution during ripening and at harvest, therefore we verify that, despite the drop in soluble solids caused by late trimming, there were no post-veraison trimming effect on concentration of total anthocyanins and tannins in berries as previously reported, ${ }^{29,38}$ but even in grape phenolic maturity ${ }^{51}$ traits during ripening, which represent a novel assessment. In particular, the main secondary metabolites involved in phenolic maturity (anthocyanins and skin tannins) increased their extractable portion during ripening in 2012 and 2013 in agreement with other studies, ${ }^{52,30}$ while during 2014, the extractable anthocyanins diminished after reaching a maximum value. The high incidence of rot close to harvest in 2014 could have promoted anthocyanins oxidation and the consequent drop in extractable anthocyanins. After sugar concentration starts to increase, susceptibility to infection by Botrytis cinerea also grows, ${ }^{53}$ which may be linked to decreases in skin thickness during ripening ${ }^{54}$ or cuticle cracking ${ }^{55}$ that often occurs in wet seasons. Following penetration of the cuticle, Botrytis cinerea facilitates cell host death by induction of oxidative burst culminating in a depletion of phenolic compounds. ${ }^{56}$ 
On the other hand, skin tannin accumulation showed minor fluctuation from veraison until harvest with no differences between treatments. This result may be caused by a dilution effect due to berry growth ${ }^{57}$ during the third stage of ripening and the ceasing of tannin biosynthesis, which occurs before veraison. ${ }^{41}$ Our results are in agreement with those reported for Sangiovese ${ }^{30}$ and Cabernet Sauvignon ${ }^{58}$ berries extracted in a winelike solution, where the value of skin tannins - and therefore their extractability - did not increase in the last phase of ripening.

Even though seeds represent a very small part of berry weight, they are a major source of phenolic compounds released in wine. The trend of extractable seed tannins in winelike solutions in this study is better explained by tannin biosynthesis which is mainly concentrated during the early developmental stages of grape and reduces after veraison. 59,60,61,62 In addition, in accordance with Allegro et al., ${ }^{30}$ the extractable seed tannins dramatically dropped after full veraison. This decline could be linked to solidification of the cells rich in tannins before harvest that could affect the aptitude for extraction of these compounds. ${ }^{63,64}$

Late trimming in our conditions affected the replenishment of carbohydrates in canes at the end of three years of trial, and it seems that a leaf-to-fruit ratio below $0.6 \mathrm{~m}^{2} / \mathrm{kg}$ is not sufficient to ensure the yearly recovery of reserves for the following years, as previously suggested by other authors. ${ }^{45,65}$

\section{CONCLUSIONS}

This study on post-veraison shoot trimming above bunch area of Sangiovese cv grown in high fertility conditions clarifies the effects of late source reduction applied over 
three consecutive years, showing the vines vegetative, productive and berry compositional responses. In highly fertile and well-watered soil, post-veraison trimming is a powerful tool for decreasing sugar concentration at harvest without affecting yield and total and extractable phenolic compounds. Nevertheless, trimmed vines at the end of the third year had reduced their starch reserves compared to the control, serving as a warning about repeated trimming over the years.

In conclusion, it is important to point out that post-veraison trimming should be applied only when the seasonal climatic conditions would lead to excessive sugar accumulation.

\section{REFERENCES}

1. Schultz HR, Climate change and viticulture: A European perspective on climatology, carbon dioxide and UV-B effects. Aust $J$ Grape Wine Res 6: 2-12 (2000).

2. Bindi M, Fibbi L and Miglietta F, Free air CO2 enrichment (FACE) of grapevine (Vitis vinifera L.): II. Growth and quality of grape and wine in response to elevated $\mathrm{CO}_{2}$ concentrations. Europ J Agron 14: 145-155 (2001).

3. Duchene E and Schneider C, Grapevine and climatic changes: a glance at the situation in Alsace. Agron Sustain Dev 25: 93-99 (2005).

4. Jones GV, Climate, grapes and wine: structure and suitability in a changing climate. Acta Hort 931: 19-28 (2012).

5. Jones GV, White MA, Cooper OR and Storchmann K, Climate change and global wine quality. Clim Change 73: 319-343 (2005). 
6. Burney JA, Kennel CF, Victor DG, Getting serious about the new realities of global climate change. Bull At Sci 69: 49-57 (2013).

7. Amerine MA., Winkler AJ, Composition and quality of musts and wines of California grapes. Hilgardia 15: 493-675 (1944).

8. Huglin $\mathrm{P}$, Nouveau mode d'évaluation des possibilités héliothermiques d'un milieu viticole. CR Acad Agr France 1117-1126 (1978).

9. Webb L, Whetton $\mathrm{P}$ and Barlow EWR, Modelled impact of future climate change on phenology of wine grapes in Australia. Aust J Grape Wine Res 13: $165-175$ (2007).

10. Schultz HR and Jones GV, Climate induced historic and future changes in viticulture. J Wine Res 21: 137-145 (2010).

11. Ganichot B, Evolution of harvesting dates in meridional Rhône. Proc. 6th Rencontres rhodaiennes, Orange, France, pp. 38-41 (2002).

12. Godden $\mathrm{P}$ and Gishen $\mathrm{M}$, Trends in the composition oà8f Australian wine. Aust NZ Wine Ind J 20: 21-46 (2005).

13. Petrie P and Sadras V, Advancement of grapevine maturity in Australia between 1993 and 2006: putative causes, magnitude of trends and viticultural consequences. Aust J Grape Wine Res 14: 33-45 (2008).

14. Palliotti A, Tombesi S, Silvestroni O, Lanari V, Gatti M and Poni S, Changes in vineyard establishment and canopy management urged by earlier climate-related ripening: a review. Sci Hort 178: 43-54 (2014). 
15. Varela C, Dry PR, Kutyna DR, Francis IL, Henschke PA, Curtin CD, et al., Strategies for reducing alcohol concentration in wine. Aust J Grape Wine Res 21: $670-679(2015)$.

16. Keller M, Managing grapevines to optimise fruit development in a challenging environment: a climate change primer for viticulturists. Aust J Grape Wine Res 16: 56-69 (2010).

17. Buttrose MS, Hale CR, Kliewer WM. Effect of temperature on composition of ‘Cabernet Sauvignon' berries. Am J Enol Vitic 22: $71-75$ (1971).

18. Kliewer WM, Torres RE, Effect of controlled day and night temperatures on grape coloration. Am J Enol Vitic 2: 71-77 (1972).

19. Mori K, Sugaya S, Gemma H. Decreased anthocyanin biosynthesis in grape berries grown under elevated night temperature condition. Scientia Hort 105: $319-330(2005)$

20. Mori K, Goto-Yamamoto N, Kitayama M, Hashizume K, Loss of anthocyanins in red-wine grape under high temperature. J Exp Bot 58 (8): 1935-1945 (2007).

21. Movahed N, Pastore C, Cellini A, Allegro G, Valentini G, Zenoni S, et al., The grapevine VviPrx31 peroxidase as a candidate gene involved in anthocyanin degradation in ripening berries under high temperature. J Plant Res 129: 513$526(2016)$.

22. Pastore C, Dal Santo S, Zenoni S, Movahed N, Allegro G, Valentini G, et al., Whole plant temperature manipulation affects flavonoid metabolism and the transcriptome of grapevine berries. Front Plant Sci 8: 929 (2017). 
23. Sadras VO, Moran MA, Elevated temperature decouples anthocyanins and sugars in berries of Shiraz and Cabernet Franc. Aust J Grape Wine Res 18: 115$122(2012)$.

24. Cortell JM, Halbleib M, Gallagher AV, Righetti T and Kennedy JA, Influence of vine vigor on grape (Vitis vinifera L. cv. Pinot noir) anthocyanins. 1 Anthocyanin concentration and composition in fruit. J Agric Food Chem 55: 6575-6584 (2007).

25. Ristic R, Downey MO, Iland PG, Bindon K, Francis IL, Herderich M and Robinson SP, Exclusion of sunlight from Shiraz grapes alters wine colour, tannin and sensory properties. Aust J Grape Wine Res 13: 53-65 (2007).

26. Cohen SD, Tarara JM and Kennedy JA, Diurnal Temperature Range Compression Hastens Berry Development and Modifies Flavonoid Partitioning in Grapes. Am J Enol Vitic 63: 112-120 (2012).

27. Teixeira A, Eiras-Dias J, Castellarin, SD and Gerós H, Berry phenolics of grapevine under challenging environments. Int J Mol Sci 14: 18711-18739 (2013).

28. Ristic R and Iland PG, Relationship between seed and berry development of Vitis vinifera L. cv. Shiraz: developmental changes in seed morphology and phenolic composition. Aust J Grape Wine Res 11: 43-58 (2005).

29. Filippetti I, Movahed N, Allegro G, Valentini G, Pastore C, Colucci E and Intrieri $\mathrm{C}$, Effect of post-veraison source limitation on the accumulation of 
sugar, anthocyanins and seed tannins in Vitis vinifera cv. Sangiovese berries. Aust J Grape Wine Res 21: 90-100 (2015).

30. Allegro G, Pastore C, Valentini G, Muzzi E and Filippetti I, Influence of berry ripeness on accumulation, composition and extractability of skin and seed flavonoids in cv. Sangiovese (Vitis vinifera L.). J Sci Food Agric 96: 4553 4559 (2016).

31. Moriondo M, Jones GV, Bois B, Dibari C, Ferrise R, Trombi G, Bindi M Projected shifts of wine regions in response to climate change. Clim Change 119: $825-839$ (2013).

32. Poni S, Casalini L, Bernizzoni F, Civardi S and Intrieri C, Effects of Early Defoliation on Shoot Photosynthesis, Yield Components, and Grape Composition. Am J Enol Vitic 57:4 (2006).

33. Friend AP and Trought MCT, Delayed winter spur-pruning in New Zealand can alter yield components of Merlot grapevines. Aust J Grape Wine Res 13: 157164 (2007).

34. Filippetti I, Allegro G, Movahed N, Pastore C, Valentini G and Intrieri C, Effect of late-season limitations induced by trimming and antitranspirants canopy spray on grape composition during ripening in Vitis vinifera cv. Sangiovese. Proc. 17th Int. GiESCO Symp., Asti-Alba, pp. 259-262 (2011).

35. Palliotti A, Gardi T, Berrios JG, Civardi S, Poni S, Early source limitation as a tool for yield control and wine quality improvement in a high-yielding red Vitis vinifera L. cultivar. Sci Hortic 145: 10-16 (2012). 
36. Gatti M, Galbignani M, Garavani A, Bernizzoni F, Tombesi S, Palliotti A and Poni S, Manipulation of ripening via antitranspirants in cv. Barbera (Vitis vinifera L.). Aust J Grape Wine Res 22: 245-255 (2016).

37. Stoll M, Scheidweiler M, Lafontaine M, Schultz HR, Possibilities to reduce the velocity of berry maturation through various leaf area to fruit ratio modifications in Vitis vinifera L. Riesling. Prog Agric Vitic 127: 68-71 (2009).

38. Palliotti A, Panara F, Silvestroni O, Lanari V, Sabbatini P, Howell GS, Gatti M and Poni S, Influence of mechanical post-veraison leaf removal apical to the cluster zone on delay of fruit ripening in Sangiovese (Vitis vinifera L.) grapevines. Australian. Aust J Grape Wine Res 19: 369-377 (2013).

39. OIV, Code des caractères descriptifs des varietès et éspèces de Vitis. OIV, Paris (1993).

40. Mattivi F, Guzzon R, Vrhovsek U, Stefanini M and Velasco R, Metabolite profiling of grape: flavonols and anthocyanins. J Agric Food Chem 54: 76927702 (2006).

41. Kennedy JA and Jones JP, Analysis of proanthocyanidin cleavage products following acid-catalysis in the presence of excess phloroglucinol. $J$ Agric Food Chem 49: 1740-1746 (2001).

42. Downey MO, Harvey JS and Robinson S, Analysis of tannins in seeds and skins of Shiraz grapes throughout berry development. Aust J Grape Wine Res 9: 15-27 (2006). 
43. Edwards EJ, Downie AF, Clingeleffer PR, A simple microplate assay to quantify nonstructural carbohydrates of grapevine tissues. Am J Enol Vitic 62: 133-137 (2011).

44. Martinez de Toda F, Sancha JC, Zheng W and Balda P, Leaf area reduction by trimming, a growing technique to restore the anthocyanins : sugars ratio decoupled by the warming climate. Vitis 53: 189-192 (2014).

45. Kliewer WM and Dokoozlian NK, Leaf Area/Crop Weight Ratios of Grapevines: Influence on Fruit Composition and Wine Quality. Am J Enol Vitic 56: 170-181 (2005).

46. Bobeica N, Poni S, Hilbert G, Renaud C, Gomès E, Delrot S, et al., Differential responses of sugar, organic acids and anthocyanins to source-sink modulation in Cabernet Sauvignon and Sangiovese grapevines. Front Plant Sci 6:382 (2015).

47. Kriedemann PE, Kliewer WM, Harris JM, Leaf age and photosynthesis in Vitis vinifera L. Vitis 9: 97-104 (1970).

48. Candolfi-Vasconcelos MC and Koblet W, Influence of partial defoliation on gas exchange parameters and chlorophyll content of field-grown grapevines. Mechanisms and limitations of the compensation capacity. Vitis 30: $129-141$ (1991).

49. Poni S, Lakso AN, Turner JR and Melious RE, Interactions of crop level and late season water stress on growth and physiology of field-grown Concord grapevines. Am J Enol Vitic 45: 252-258 (1994). 
50. Poni S, Gatti M, Bernizzoni F, Civardi S, Bobeica N, Magnanini E, Palliotti A, Late leaf removal aimed at delaying ripening in cv. Sangiovese: physiological assessment and vine performance. Aust J Grape Wine Res 19: 378-387 (2013).

51. Glories Y, Augustin M, Maturité phénolique du raisin, consèquences technologiques: applications aux millésimes 1991 et 1992. Actes du Colloque “Journée technique du CIVB” 21 Janvier, Bordeaux, p. 56 (1993).

52. Río Segade S, Vásquez ES and Losada ED, Influence of ripeness grade on accumulation and extractability of grape skin anthocyanins in different cultivars. J Food Comp Analysis 21: 599-607 (2008).

53. Mundy DC, Beresford RM, Susceptibility of grapes to Botrytis cinerea in relation to berry nitrogen and sugar concentration. NZ Plant Prot 60:123-127 (2007).

54. Keller M, Arnink KJ and Hrazdina G, Interaction of nitrogen availability during bloom and light intensity during veraison. I. Effects on grapevine growth, fruit development, and ripening. Am J Enol Vitic 49: 333-340 (1998).

55. Commenil P, Brunet L, Audran JC, The development of the grape berry cuticle in relation to susceptibility to bunch rot disease. $J$ Exp Bot 48: 1599-1607 (1997).

56. Van Kan JAL, Licensed to kill: the lifestyle of a necrotrophic plant pathogen. Trends Plant Sci 11: 247-253 (2006). 
57. Melo MS, Schultz HR, Volschenk CG and Hunter JJ, Berry size variation of Vitis vinifera L. cv. Syrah: morphological dimensions, berry composition and wine quality. S Afr J Enol Vitic 36:1-10 (2015).

58. Bindon KA, Hadi Madani S, Pendelton P, Smith PA and Kennedy JA, Factors affecting skin tannin extractability in ripening grapes. J Agric Food Chem 62: 1130-1141 (2014).

59. Pastor Del Rio JL and Kennedy JA, Development of proanthocyanidins in Vitis vinifera L. cv. Pinot noir grapes and extraction into wine. Am J Enol Vitic 57: 125-132 (2006).

60. Takos AM, Jaffé FW, Jacob SR, Bogs J, Robinson SP, Walker AR, Lightinduced expression of a MYB gene regulates anthocyanin biosynthesis in red apples. Plant Physiol 142: 1216-1232 (2006).

61. Castellarin SD, Matthews MA, Di Gaspero G, Gambetta GA, Water deficits accelerate ripening and induce changes in gene expression regulating flavonoid biosynthesis in grape berries. Planta 227: 101-112 (2007).

62. Hanlin RL and Downey MO, Condensed tannin accumulation and composition in skin of Shiraz and Cabernet Sauvignon grapes during berry development. Am J Enol Vitic 60: 13-23 (2009).

63. Kennedy JA, Matthews MA, Waterhouse AL, Changes in grape seed polyphenols during fruit ripening. Phytochemistry 55: 77-85 (2000). 
64. Cadot Y, Miñana-Castello MT and Chevalier M, Anatomical, histological, and histochemical changes in grape seeds from Vitis vinifera L. cv. Cabernet franc during fruit development. J Agric Food Chem 54: 9206-9215 (2006).

65. Howell GS, Sustainable grape productivity and the growth-yield relationship: a review. Am J Enol Vitic 52: 165-174 (2001).

FIGURE CAPTIONS

This article is protected by copyright. All rights reserved. 
Figure 1. Concentration of total soluble solids in berries of control (C) and postveraison trimmed (TRIMM) Sangiovese vines in 2012 (A), 2013 (B) and 2014 (C). Arrowheads indicate time of trimming. Data are means $(n=4)+/-$ standard error. Asterisks indicate significant differences between treatments within data according to the Tukey test Pd0.05.

Figure 2. Concentration of extractable anthocyanin in berries of control (C) and postveraison trimmed (TRIMM) Sangiovese vines in 2012 (A), 2013 (B) and 2014 (C). Arrowheads indicate time of trimming. Data are means $(n=4)+/-$ standard error.

Figure 3. Concentration of extractable tannin in berry skins of control (C) and postveraison trimmed Sangiovese vines (TRIMM) in 2012 (A), 2013 (B) and 2014 (C). Arrowheads indicate time of trimming. Data are means $(n=4)+/-$ standard error. Asterisks indicate significant differences between treatments within data according to the Tukey test Pd0.05.

Figure 4. Concentration of extractable tannin in berry seeds of control (C) and postveraison trimmed Sangiovese vines (TRIMM) in 2012 (A), 2013 (B) and 2014 (C). Arrowheads indicate time of trimming. Data are means $(n=4)+/-$ standard error. Asterisks indicate significant differences between treatments within data according to the Tukey test Pd0.05. 
Table 1. Seasonal trend from April $1^{\text {st }}$ through September $30^{\text {th }}$ in 2012, 2013 and 2014.

\begin{tabular}{cccc}
\hline & 2012 & 2013 & 2014 \\
\hline Total rainfall $(\mathrm{mm})$ & 288 & 253 & 377 \\
Average air temperature $\left({ }^{\circ} \mathrm{C}\right)$ & 21.4 & 20.5 & 19.9 \\
Minimum air temperature $\left({ }^{\circ} \mathrm{C}\right)$ & 14.0 & 14.1 & 13.9 \\
Maximum air temperature $\left({ }^{\circ} \mathrm{C}\right)$ & 28.7 & 26.7 & 22.7 \\
\hline
\end{tabular}


Table 2. Leaf area, yield components, must composition and leaf to fruit ratio recorded at harvest in Sangiovese vines subjected to late trimming applied in post-veraison (TRIMM) and in control vines (C). Data averaged over 2012-2014.

\begin{tabular}{lccc}
\hline \multicolumn{1}{c}{ Parameters } & C & TRIMM & Year effect \\
\hline Total LA after trimming $\left(\mathrm{m}^{2} / \mathrm{m}\right)$ & $6.39 \mathrm{a}$ & $2.11 \mathrm{~b}$ & $\mathrm{NS}$ \\
Bunches $(\mathrm{n} / \mathrm{m})$ & 14 & 14 & $\mathrm{NS}$ \\
Yield $(\mathrm{kg} / \mathrm{m})$ & 4.63 & 4.56 & $*$ \\
Bunch mass $(\mathrm{g})$ & 337 & 341 & $\mathrm{NS}$ \\
Berry mass $(\mathrm{g})$ & 2.79 & 2.75 & $\mathrm{NS}$ \\
Rot incidence $(\%$ of surface area bunch infected) & 12.5 & 9.4 & $*$ \\
Total soluble solids $\left({ }^{\circ}\right.$ Brix $)$ & $21.7 \mathrm{a}$ & $20.3 \mathrm{~b}$ & $\mathrm{NS}$ \\
Titratable acidity $(\mathrm{g} / \mathrm{L})$ & 7.40 & 7.12 & $\mathrm{NS}$ \\
$\mathrm{pH}$ & 3.39 & 3.40 & $\mathrm{NS}$ \\
Leaf-to-fruit ratio $\left(\mathrm{m}^{2} / \mathrm{kg}\right)$ & $1.48 \mathrm{a}$ & $0.55 \mathrm{~b}$ & $\mathrm{NS}$
\end{tabular}

Means within rows designated by different letters are significantly different according to Tukey test. Asterisks indicate significance at Pd0.05; NS, not significant. No interaction was found between years and treatments. 
Table 3. Total and extractable anthocyanins, skin tannins and seed tannins at harvest in Sangiovese vines subjected to late trimming applied in post veraison (TRIMM) and in control vines (C). Data averaged over 2012-2014.

\begin{tabular}{lccc}
\hline \multicolumn{1}{c}{ Parameters } & C & TRIMM & Year effect \\
\hline Total anthocyanins $(\mathrm{mg} / \mathrm{kg})$ & 627.5 & 664.9 & $\mathrm{NS}$ \\
Extractable anthocyanins $(\mathrm{mg} / \mathrm{kg})$ & 91.6 & 89.9 & $\mathrm{NS}$ \\
Anthocyanin extractability $(\%)$ & 13.9 & 14.6 & $\mathrm{NS}$ \\
\hline Total skin tannins $(\mathrm{mg} / \mathrm{kg})$ & 992.7 & 906.2 & $*$ \\
Extractable skin tannins $(\mathrm{mg} / \mathrm{kg})$ & 420.6 & 404.8 & $*$ \\
Skin tannins extractability $(\%)$ & 58.3 & 54.7 & $\mathrm{NS}$ \\
\hline Total seed tannins $(\mathrm{mg} / \mathrm{kg})$ & 1335.2 & 1332.2 & $\mathrm{NS}$ \\
Extractable seed tannins $(\mathrm{mg} / \mathrm{kg})$ & 629.9 & 612.6 & $*$ \\
Seed tannins extractability $(\%)$ & 49.9 & 48.9 & $\mathrm{NS}$ \\
\hline
\end{tabular}

Asterisks indicate significance at Pd0.05; NS = not significant. No interaction was found between years and treatments. 
Table 4. Pruning weight and carbohydrates level in cane woods of Sangiovese vines subjected to late trimming applied in post veraison (TRIMM) and in control vines (C). Samples taken in March 2015.

\begin{tabular}{cccc}
\hline & $\begin{array}{c}\text { Pruning weight } \\
(\mathrm{kg} / \mathrm{m})\end{array}$ & $\begin{array}{c}\text { Starch } \\
(\mathrm{mg} / \mathrm{g} \text { dry } \mathrm{wt})\end{array}$ & $\begin{array}{c}\text { Soluble sugars } \\
(\mathrm{mg} / \mathrm{g} \text { dry wt })\end{array}$ \\
\hline $\mathrm{C}$ & $1.10 \mathrm{a}$ & $76 \mathrm{a}$ & 37 \\
TRIMM & $0.49 \mathrm{~b}$ & $54 \mathrm{~b}$ & 30
\end{tabular}

Means within columns designated by different letters are significantly different according to Tukey test $(\operatorname{Pd} 0.05)$. 

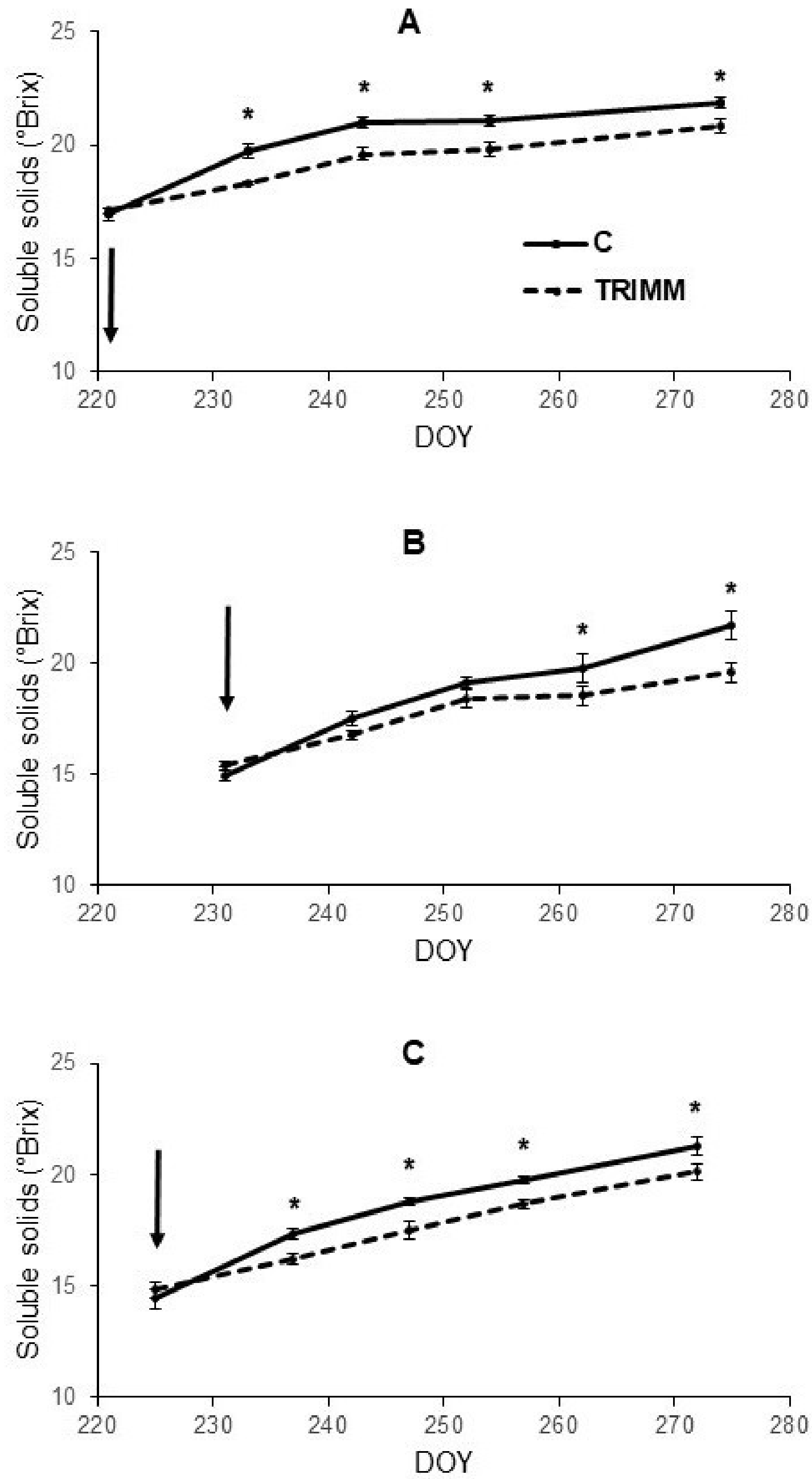

Figure 1.jpg

This article is protected by copyright. All rights reserved. 


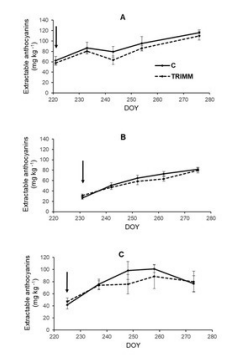

Figure 2.jpg

This article is protected by copyright. All rights reserved. 

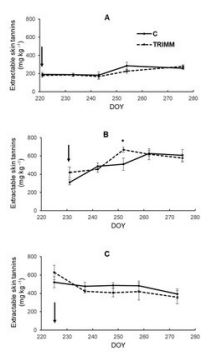

Figure 3.jpg

This article is protected by copyright. All rights reserved. 


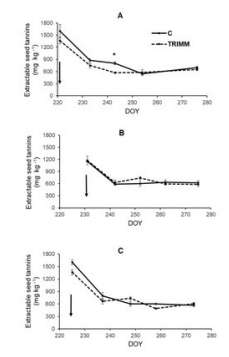

Figure 4.jpg

This article is protected by copyright. All rights reserved. 